\title{
WHAT CONSTITUTES “GOODNESS" IN FARMING? FARMING AND LOCAL COMMUNITY IN NEOLIBERAL CONTEXT IN JAPAN
}

\author{
Masashi Tachikawa $^{1^{*}}$, Kiyohiko Sakamoto \\ ${ }^{1}$ Graduate School of Environmental Studies, Nagoya University, Japan \\ ${ }^{2}$ Graduate School of Agriculture, Kyoto University, Japan \\ *Corresponding author: mtachi@nagoya-u.jp
}

Citation: Tachikawa, M., Sakamoto, K., 2017. What Constitutes "Goodness" in Farming? Farming and Local Community in Neoliberal Context in Japan. J. Asian Rur. Stud. 1(2): 134-144

\begin{abstract}
Japanese agriculture has been going through a drastic change especially in terms of the number of farmers today. Modernization of agricultural structure, which had been pursued for many years by the government, seems to be suddenly realized through a large scale retirement of elder farmers. The advancing structural change in farming, especially consolidation of farming into fewer agricultural entities, raises a concern that rural community people are completely detached from farming per se. This concern leads our study to analyze the relationship between large-scale farming entities and local communities, which were once closely tied. In order to understand the nature and change of the relationship, we have focused on a Japanese farm competition and try to elucidate how the "desirability" of farms have evolved over time, and try to draw implications for the above-mentioned relationship. Our examinations of selection criteria of agricultural competitions, where advanced farmers seek to be awarded as the "best" farmers, reveal that the criteria have evolved from simpler ones to highly complex ones. More specifically, in an early era (the 1960s), farmers competing there are expected to have almost solely technical skills, whereas more recent criteria dictate that farmers should make social contribution to local communities. This indicates that goodness or "desirability" for advanced farmers has also gone through substantial changes. Farming entities are now not only to survive market competitions, but also to confront and deal with complex local demands to play roles that used to be fulfilled by local governments faced with declining budgets from the state government. The fact that Japanese cutting-edge farmers are expected to play substantial roles to sustain local communities seems to resonate with discourses extolled by neoliberalism penetrating into rural areas across the world. That is, rural actors are supposed to be entrepreneurial, efficient, and competitive in market principles, and simultaneously required to make contradictory commitments to sustain local communities.
\end{abstract}

Keywords: Japan; agricultural competitions; neoliberalism; large-scale farmers 


\section{Introduction}

It has been argued that Japanese agriculture, especially paddy field agriculture, has been faced with grave problems, such as small-scale operation and aging of farmers. However, while the so-called Showa One-digit Generation people, those who were born between 1926 and 1935, have almost completely retired in recent years, a drastic decrease in agricultural workers is happening today, and, accordingly, the scale of farm management is rapidly increasing. The continuous decline of price of rice also urges farmers to enlarge their operation for better economy of scale.

Recent statistical data attest to said trends (Yagi et al., 2017). In the decade from 2005 to 2015, the number of farms with less than 1 ha of tracts decreased by about $40 \%$, whereas the stratum of farms with 10 ha or more grew by 1.7 times. Among this stratum, the number of farms with 30 to 100 ha tripled from 1,131 to 3,687; the number of farms with 100 ha or more almost quintupled from 45 to 225 . The expansion of the acreage was accompanied with growth in business size (i.e., sales amount) of these farm entities. Over $70 \%$ of farming entities with 100 ha or more recorded 50 million yen or more in their sales, which is roughly equivalent to US\$0.5 Million.

The changes mentioned above occurred in the brief period of the past ten years. Such a rapid structural transformation of paddy production in Japan has not only resulted in consolidation of farming businesses into large-scale entities, which are more commonly observed in Hokkaido, Tohoku, Kanto, and Hokuriku, but also left significant impacts on rural societies across the country. In his presentation at an academic conference, Yanagimura (2016) discussed growing incongruity between policies for structural reform and concerns for sustaining rural societies. He argued that the advancing agricultural structural change is prone to exacerbate hollowing-out of rural communities and agricultural sectors will be disintegrate from rural societies especially in Hokkaido and Tohoku. In other words, the basic premise for survival and sustainability of rural societies is going through a critical phase. Accordingly, a radically new alternative for sustenance of rural sectors is being sought such that large-scale farming entities are expected to play vital roles in managing rural and farming resources, and by doing so, to transform traditional organizations. It is against this backdrop that increasing attention is being drawn to "agricultural enterprises (No-Kigyo)" (Oda et al., 2013).

To better grasp the condition described above, a clear understanding of historical changes in relationships between rural societies ( $m u r a$ ) and farm entities (mostly family farms) in Japan, as characterized as follows, is indispensable. In a typical rural society where farmers sustain their lives, they would have a vested interest in farmland ownership. Farmlands are not just an economic good but have symbolic meanings. One of such symbolic functions is to guarantee a membership status of a household within the community. Likewise, in Japan, farming activities, such as control of water flow and farm roads, have always been collaboratively done and hence served to maintain strong social relationships within rural communities. As rural resource management is an important common task for rural communities, large-scale farms that frequently lease lands from other community members have to carefully handle rented tracts, willingly cooperate in community activities, and observe the community's norms, to prevent possible tensions with the community. 
In the near future, however, the relationship between rural society and large-scale farms, such as large agricultural corporations, may be altered drastically from the circumstance described above. That is, as generation goes, a substantial portion of members of contemporary rural communities may no longer be as much interested in agricultural lands as in the past (Godo, 2006). It may be said that a rural community will become just a loosely connected association of people living in a place as typically found in urban areas, or a group of mere landowners with no interest in committing themselves to management of their lands. Thus, management of rural resources (rivers, roads, shared properties, etc.) is increasingly burdensome for rural residents; nonetheless, cooperation among themselves can hardly be expected. A possible scenario, therefore, is that a certain portion of large-scale agricultural corporations take over the function undertaken by traditional rural communities in sustaining proper rural resource management. Indeed, percentage of large-scale farming corporations engaging in rural resource management seems to be significantly increasing. Also, cooperation and commitment by a growing number of diverse individuals and organizations outside the rural society, such as non-profit organizations and urban residents, will become important.

As noted above, as the relationship between rural societies and large-scale farms is changing, expectations on roles played by the latter are also changing. Shifting compositions of farming and non-farming residents, accompanied with waning vitality of communities in rural areas, can trigger urge for larger contributions by large scale farmers to maintaining rural resources as well as rural communities per se. Against this backdrop, we argue that the desirability, or what constitutes "goodness" of farming, is also evolving today. With this in mind, the purpose of this paper is to characterize changes in the goodness of farming during the last several decades.

To achieve this, following a brief review of literature on Japanese rural sociology in which this study is situated, we analyze changes in criteria for a series of an agricultural competition in which farming entities with highly advanced production techniques and business management compete for recognition as the best farm in Japan. The agricultural competition can be considered a showcase for the future of farming by recognizing the most desired farms. Therefore, the examination criteria in the competition is expected to reflect the ideal image of farming, as well as agricultural and social conditions surrounding it, in different time periods. In the analysis below, we illuminate how the desirable relationship between farming and the community has altered by examining historical changes in the judging standards for the competition.

\section{Literature Review}

Rural sociology in Japan has tended to revolve around analyses of mura, which could be translated as rural villages, hamlets, or communities. Analytical emphases were on lives of mura entwined with its historically developed structure. However, recent theoretical and empirical developments in sociology of food and agriculture (SFA), which emerged in the US rural sociology after the late 1980s, have made substantial impacts on Japanese rural sociology. Some of remarkable changes brought by SFA to Japanese rural sociology include analytical perspectives that transcend from the mura level to the global level and integrate agriculture and food into studies of rural areas 
(Masugata et al., 2014; Tachikawa, forthcoming).

For scholars pursuing SFA, one of the most imminent issues relevant to transitions of rural areas and agri-food sectors is neoliberalism (Masugata et al., 2014). Indeed, a wide array of phenomena attributed to neoliberalism, such as penetration of market rules, globalization of agriculture and food provision systems, reinforcement of entrepreneurship, and reduction of fiscal expenditures for rural sectors, all seem to be undeniably affecting rural sectors. Despite, or maybe because of, such magnitude of impacts on rural sectors, as some critiques have argued, neoliberalism might have been grasped as a singular, monolithic, and cohesive idea or phenomenon (Larner, 2000; Peck and Tickell, 2002). This understanding might be not so problematic as long as neoliberalism was embodied in relatively simplistic, "roll-back" manners (Peck and Tickell, 2002; Lockie and Higgins, 2007) in which the state (national) government would withdraw its roles, slash social expenditures, and drive deregulations, as exemplified by Thatcher's and Reagan's administrations in the 1980s.

Nonetheless, manners through which neoliberalism materializes as policies and affects society have become way complex than in the 1980s. In fact, what better characterizes more recent "roll-out" neoliberalism where the state government takes covert but substantial roles in promoting economy and controlling society (Peck and Tickell, 2002; Lockie and Higgins, 2007) is its multifaceted, variegated, hybrid-like, and oftentimes even contradictory, nature (Sakamoto, 2016). The state would set up a variety of political techniques that can lead individuals or organizations to self-disciplining, self-control and self-training (Barry et. al., 1996). Through fostering self-disciplining capability, each actor is expected to cope with and survive in market principles, a hallmark of neoliberalism.

One such example of mechanisms to foster self-disciplined and competitive capacity is the use of discourses that honor exemplary model cases, which other actors are expected to follow (Iba and Sakamoto, 2013; Tachikawa, forthcoming). "White Paper of Agriculture," or Annual Report on Food, Agriculture and Rural Area in Japan, a governmental publication aiming at general citizens, for instance, contain a plenty of stories and narratives that depict success-stories of farmers, farmers groups, or other relevant organizations in rural areas. A message, as tacitly conveyed through those cases, is that other rural actors should learn from those good case and follow the pioneers' paths, if not completely same. Likewise, agricultural competitions, the theme of our paper, are considered arenas of discourses that exhibit the "best" farmers or farming entities to be followed by others.

Our intention in the analysis lies in not simply capturing historical changes in selection criteria of agricultural competitions, but situating changing criteria in a broader socio-economic transition from the post-World-War-II productivist rural or farming policies to emerging neoliberalism that we suppose are penetrating into rural sectors of Japan.

\section{Methods}

To analyze the goodness of farming, we examined selection criteria in the "National Agricultural Competition" (Zenkoku Nogyo Concours). This competition started in 1952 to celebrate the 70th anniversary of the publication of the Mainichi Shimbun, one of the 
major national newspapers in Japan. Although the organizer of the competition is the Mainichi Shimbun company, it was once a joint project by the Mainich and an affiliated association, "Fumin Association". The aim of the competition is to "honor advanced and creative agricultural producers who develop outstanding farm management based on cultivation techniques devised by innovative ingenuity" (excerpts from the "Participation Procedure" in 2016).

For the analysis, we collected records of selection and awarding criteria of the competition and analyzed their contents. The records of criteria were collected from the database of the National Diet Library of Japan. Duet to the limited availability of data, we were unable to obtain criteria for all the years from the establishment of the competition. Also, because of time constraint, we focused on only one competition.

According to the records we managed to collect, the selection criteria were not clearly stated during the early time period of the competition whereas only the examination procedure was specified. It seems that after the first years, as the competition was taking a tangible and distinct shape, the criteria were also getting clarified.

In our analysis, beginning with the year of 1965 when only the participation procedure was confirmed to be established, we compared selection criteria at three other points in time including 1981, 1993, and 2016 in order to illuminate transition of ideas underlying the goodness of farming.

\section{Changing "Desirability" of Farming}

Tables below summarize contents of selection criteria or procedure for the four points of time, 1965, 1981, 1993, and 2016. We paid special attention to how each criterion was put in order, assuming that more important criterion tends to come first. A general trend we can grasp from the tables is that the examination criteria have been gradually developed from simple ones to more complex ones, demonstrating a shift of a narrower focus on technological advancement to a broader scope including contribution to local community. In other words, the "desirability" of farming has become much complicated today and inclusive of diverse perspectives.

Table 1: The examination procedure of 1965

\footnotetext{
1. Jury members corresponding to the subject area will judge from a technological viewpoint.

2. Each specialized subcommittee will be opened, and the chief inspector will review the examiners' judgment.

3. Except for the production technology and rural living areas, the dossier is circulated to farm management committee and judged accordingly.

4. All dossier will be reviewed by the subcommittee and create a draft representative of the district. (Hereinafter abbreviated)
}

Note: Standards are not explicitly stated this year.

Source: Participants' Guide for the 14th National Agricultural Competition, Nogyo Fumin

37(2): 80-81、(Feb, 1965) 
Table 2: Award Selection Criteria in 1981

1. Is it correct from a scientific point of view?

2. Is creative ingenuity being done?

3. Is it in the direction of modernization, expansion, and is there any progressive aspect?

4. Whether labor savings are considered?

5. Whether it has possibility of diffusion beyond the community and has stability?

6. Technology and management are outstanding in the region?

In addition to the above, at the national convention, the results of the presentation will be scored taking into account their realities.

Source: Participants' Guide for the National Agricultural Competition, Nogyo Fumin 53(12)

177-181 (Nov, 1981)

Table 3: Award Selection Criteria in 1993

1. Is it correct from a scientific point of view?

2. Is creative ingenuity being done?

3. Is it in the direction of modernization, expansion, and is there any international aspect?

4. Whether labor savings are considered?

5. Whether it has possibility of diffusion beyond the community and has stability?

6. Technology, management and living are outstanding in the region?

In addition to the above, at the national convention, the results of the presentation will be scored taking into account their realities.

Source: Participants' Guide for the National Agricultural Competition, Fumin 65(13): 129-135

(Dec, 1993)

Table 4: Award Selection Criteria in 2016

(1) Pioneering ingenuity has been tried in each aspect such as acquisition method of production means, production technology, sales method of products, farm management, cooperative organization, or living improvement and community revitalization? And do they succeed?

(2) Are there any ingenuity regarding the utilization of machinery and facilities which is consistent with the innovation of the entire management?

(3) As a result of these innovative activities related to management and daily life, do they have obtained management's sustainability in response to management efficiency, profitability, safety, environmental change, or spiritual and material richness of life? And do that level outweigh the average of the region?

(4) Are they keen on generating successors of their own farms and local society, and caregivers for living for the elderly?

(5) Is there a well-worked environment for both men and women so that women can demonstrate their abilities?

(6) Do they disseminate excellent management methods to the local community, or are they contributing to the community by developing leadership in cooperative organizations and/or community revitalization?

(7) Are they giving due attention to food safety, environmental conservation, creating a comfortable society, and exchanging and collaborating with other people?

Source: Participants' Guide for the 65th National Agricultural Competition. (http://www.mainichi.co.jp/download/agri2016.pdf) 
Following are observations obtained through analyzing changes in examination criteria at the National Agricultural Competition shown above:

1. As can be clearly seen in the examination procedure in 1965 and the examination criteria in 1981, the most important examination benchmark was to excel in agricultural technologies. Special importance lies in whether candidate's technical excellence is backed up by science as evinced with the "scientific correctness" placed at the beginning of the examination criteria in 1981 and 1993. Scientific legitimacy is crucial here, since farm policies in these years were typically characterized as productivist (Tachikawa, 2005). In other words, alternative technologies, such as organic agriculture, which cannot be properly positioned in modern science and technology, are considered out of the scope of evaluation.

2. What is emphasized after the technological excellence are farmer's ability to enlarge scale of farming operation and farm management skill to efficiently save labor. Furthermore, included in the criteria was potential to disseminate such farm management skills to surrounding areas. In the selection procedure in 1965, the technical aspect was the first criterion followed by the farm management. A crucial point in judgement is whether a farm under selection could excel the average level of fellow farmers in the same region in both technical and farm management aspects. The emphasis on technical excellence and farm management could be seen as reflection of the dominant orientation of farm policies in Japan under the Basic Agricultural Law. This law was enacted in 1961, aiming for modernization and scale expansion of farm management to fill the then growing gap in income level between farmers and employees in other industries. Although the Basic Agricultural Law was replaced by a new basic law in 1999, the legacy of the old basic law seems to have lasted such that the contents of the selection standards highlighted technical excellence and farm management until the 1990s.

3. Compared to the selection criteria of the 1993 competition, the 2016 version exhibits a significant difference. Especially in 2016, not only the excellence in technological mastery and management, commitment to activities by farms to contribute to local societies was incorporated into the criteria. More specifically, diverse activities for social contribution undertaken by farms, such as "Revitalizing local community", "Generate successors and people of local society", "Caregiving for living for the elderly", and "Exchange and collaborate with other people", are included in the criteria. Compared with the agricultural modernization, scale expansion, and labor saving under the Basic Agricultural Law, the attention to social aspects of contributions by farms, as incorporate in the 2016 criteria, seems to exhibit a fresh viewpoint. Although every farm in a competition does not have to meet all the criteria, it can be argued that the "image of desirable farming" has changed dramatically from the previous standard. In addition to the technologies and management excellence, the latest criteria highly appreciate farmers' diverse relationships with local communities and contribution to their revitalization. 
The change in the selection criteria indicates that expectations for farming in local communities is becoming even more complicated. Lockie and Higgins (2007) draws our attention to a phenomenon in which farming entities in Australia have become faced with complex expectations to be not only profitable and competitive to survive through efficient management, but also environmentally responsible through non-farming activities, such as enrollment into the Landcare movement. To refer to this complicated condition surrounding modern Australian farmers, Lockie and Higgins (2007) employ a word "hybrid assemblage" and associate the complex, sometimes contradicting, expectation to neoliberal governmentality. We can reasonably assume that the same phenomenon can be seen in Japan as we have observed above.

\section{Discussion}

As described above, the change in the selection criteria on farm management has become increasingly more complex over the time. Managers of farming entities are required to respond to complex expectations from different fields. For them it is considered desirable to build more symbiotic relationships with local communities. It means that desirability of farm management can no longer be evaluated by simple dimensions, such as profitability and efficiency.

This situation in which farm entities are faced with complex expectations resonates with what Shuraku Einou, or community farm enterprises (CFEs), have been going through recently. A Shuraku Einou is a group of farming community members of collectively engaged in farming, oftentimes jointly owning agricultural equipment and arranging labor, CFEs are expected to undertake effectively and efficiently substantial roles to sustain viable farming in rural areas (Iba and Sakamoto, 2013). Thus, "CFE as a key player in regional agriculture is not only expected to survive market competition by establishing efficient management and demonstrating entrepreneurial spirits, but also contribute to sustaining social and community lives in rural areas in a time where public services are in decline" (Sakamoto, forthcoming). In a similar vein, a variety of farming entities have come to engage in diverse social businesses in conjunction with agriculture (e.g, farmers' direct sales and agriculture-welfare collaborative project); and now such actions beyond farming are called "social contribution endeavors by farming entities" (Kataoka, 2016) in Japan.

CFEs and farming entities engaged in social contribution endeavors demonstrate their efficient management, entrepreneurship and commitment to local communities are widely publicized through different media, including governmental documents, newspapers or social network platforms. Discourses praising exemplary CFEs and social contribution endeavors would be disseminated such that and desirable and ideal models of farming entities are popularized. There is no doubt that contemporary images of desirable farmers are reflected and incorporated in selection criteria of agricultural competitions.

The context against which changes in "goodness" of farming have occurred is, in our view, deeply rooted in growing neoliberalism or neoliberal governmentality (see Sakamoto (forthcoming) for further details). The idea that it is desirable that such farming entities also contribute to the local community somehow shows the fact that neoliberalism has penetrated our society. At the level of local community, cutbacks in 
the government's financial supports under neo-liberalism have become palpable, while and self-help type of efforts are encouraged by the government. Under neoliberalism, the national government, which would promote entrepreneurship by farming entities while substantially curtailing fiscal commitments, seems to keenly propagate discourses on desirable farming entities to society.

For stakeholders in rural areas where already have suffered from aging population and stagnant economy, the impossibility for fiscal dependence on the national government signals desperate needs for alternative ways to sustain people's lives. Thus, cooperation with large-scale farming bodies comes in as one of few remaining recourses. According to Peck and Tickell's (2002) terminology, the shift in which the government withdraws its active roles in supporting social lives perhaps indicates a political economic current where "roll-back" neo-liberalism plays out. Roll-back neo-liberalism, as pursued by Thatcher and Reagan administrations in the 1980s, would pursue "smaller government" by slashing the state's fiscal expenditure resulting in curtailment of regional supports.

However, as pointed out by Peck and Tickell (2002), neo-liberalism has evolved into roll-out where the government takes on tacit roles in controlling society through a variety of political techniques towards self-disciplining by individuals, including adoption of self-auditing and monitoring, use of private standards a certification, and so forth. These self-disciplining mechanisms are to encourage individuals to adapt to and survive in market principles, which infiltrate into every aspect of social lives. Thus, business managers, for instance, are supposed to thoroughly self-manage and simultaneously to survive market competition in accordance with new code of conduct. Thus, honing management skills under self-discipline is a "must have" ability for manages of business entities, whether farming or not, to survive increasing harsh market competition. In the public administration domain, the new public management (NPM) has been gaining growing attention, which calls for collaborative work between government and local citizens (Okuno and Kurita, 2010).

Amidst the diffusion of roll-out neo-liberalism, encouraging people to contribute to local society suggests that Japanese famers in this context are faced with diverse demands that could go against pursuit of economic efficiency. As we have pointed out above, farmers in Australia have been faced with competing rationalities, that is, one pursuing environmental sustainability and the other pursuing economic efficiency. It can be reasonably assumed that, also in Japan, large-scale farming entities are expected to fulfill contradictory, or in some cases even more complicated, tasks to deal with demands and norms at the local level while steering its business management to survive today's tough market competition.

\section{Conclusion}

Japanese agriculture is now going through a radical change especially in terms of number of farms. As the structure of Japanese agriculture alters, the relationship between farms and local societies would evolve into a different context, as we have discussed above. The "goodness" of farming, or what a good farm should look like, can be altered in a social context where every farm exists, survive, or maybe thrives. There is no single solution for optimal relationships between farms and local societies, which 
farm economists oftentimes might assume.

Farms and local communities in Japan, which once were closely tied each other, seem to have been disconnected not least because of productivist policies introduced and pursued after the World War II. More recently, however, palpable drawbacks of the disconnection have come to sparked debates among scholars and policymakers over how farms and local communities should create symbiotic relations among them. Admittedly, this question still remains open. For some, this signals an ideal move back to the long-standing peasant tradition, or re-peasantization. For others, this indicates further penetration of roll-out neoliberalism and tacit exploitation of rural people. Or, both views may hold true at the same time. We have no definite answer now, which may be given by the next generation.

\section{References}

Barry, A., Osborne, T. and Rose, N. S. (1996) Foucault and Political Reason: Liberalism, Neo-liberalism, and Rationalities of Government, University of Chicago Press, Chicago

Godo, Y. (2006) Nihon no Shoku to No: Kiki no Honshitsu (Food and Agriculture in Japan: The Nature of Crisis), NTT Publishing.

Iba, H. and K. Sakamoto (2013) "Beyond Farming: Cases of Revitalization of Rural Communities through Social Service Provision by Community Farming Enterprise" in S. Wolf and A. Bonanno (eds.), The Neoliberal Regime in the Agri-Food Sector: Crisis, Resilience and Restructuring. Routledge Books. pp.129-149.

Kataoka, M. (2016) "Basic Concept and its Nature of Enterprise Creating Social Values" in Iba, H., A. Takahashi, and M. Kataoka eds. Creating Social Values in the Rural and Farm Sector: Theories and Case Studies, Norin Tokei Shuppan.

Larner, W. (2000) "Neo-Liberalism: Policy, Ideology, Governmentality" Studies in Political Economy, 63, 5-25.

Lockie, S. and V. Higgins (2007) "Roll-out neoliberalism and hybrid practices of regulation in Australian agri-environmental governance," Journal of rural studies 23: $1-11$.

Masugata, T., Y. Taniguchi and M. Tachikawa (2014) Shokuto Nou no Shakaigaku, Minerva.

Okuno, N. and T. Kurita (2010) Atarashii Koukyo wo Ninau Hitobito (People Involving New Public Management), Iwanami Shoten.

Peck, J. and Tickell, A. (2002) "Neoliberalizing Space", Antipode, 34(3), 380-404.

Sakamoto, K. (2016) "Shakai-koukengata-jigyou no seijikeizaigakuteki-haikei: Shin-jiyu-shugi no rekishi-teki tenkai ni chakumoku shite (Political economic background of social contribution endeavors by farming entities: with an emphasis on historical development of neoliberalism)" in H. Iba, A. Takahashi and M. Kataoka (eds.) Nougyou nouson ni okeru shakai kouken gata jigyou ron (Social contribution endeavors by farming entities in farming and rural areas), Norintokeishuppan, 69-90.

Sakamoto, K. (forthcoming) "Farms on the Cutting-edge of Innovation: A Sociological Analysis on the Relevance of Local Agriculture and Community under Neoliberal 
Governmentality," Nogyo Keizai Kenkyu (Japanese Journal of Rural Economics) $89(2)$.

Tachikawa, M. (2005) "Transition to Post-productivism and Change of Gaze toward the Rural in Japan," Annual Bulletin of Japanese Association for Rural Studies No.41: 7-40.

Tachikawa, M. (forthcoming) "Comments to Presentation by Sakamoto," Nogyo Keizai Kenkyu (Japanese Journal of Rural Economics) 89(2).

Yagi, H. et al. (2017) Chiiki to tomoni ayumu Daikibo Suiden Nogyo heno Chosen (Challenges of Large Scale Paddy Farming in Local Society), Nosan Gyoson Bunka Kyokai. 